though they are given some discretion to handle the redistribution as they think best.

(4) The repercussions on postgraduate training and teaching, especially in the regional or peripheral hospitals, have been completely ignored, and the local consultants, as usual, are left to salvage what they can out of the resulting chaos.

I feel that it is most important that colleagues in our NHS hospitals should have an opportunity to express their views on an important matter such as this before we are all presented with the usual fait accompli. I would like respectfully to submit that the current staffing inequalities and chaos can be solved only by a radical rethink of the whole problem instead of tinkering with the tip of the iceberg.

G I B DA CosTA

Shotley Bridge General Hospital,

Consett, Co Durham

' Hospital Staffing Structure (Medical and Dental) Second Progress Report, British Medical fournal
Supplement, 1971, 3, 119.

\section{New consultant contract}

SIR,-In your leading article "Proceed with the pricing" ( 1 July, p 4) you state that the result of the ballot on the new contract "confirms the favourable reception given ... a the countrywide meetings of consultants addressed by the chairman [of the Central Committee for Hospital Medical Services] and his senior colleagues." This is hardly surprising if the meeting held at BMA House was typical. The views expressed from the platform were so favourable and enthusiastic (some might even say one-sided) that many consultants were bound to leave the Great Hall with the feeling that a new dawn was about to break. It is therefore a matter of concern that an adequate presentation of the drawbacks and pitfalls in the proposals (such as that by Mr T McFarlane (17 June, p 1647)) did not appear in your columns until the ballot had closed.

Let us be under no illusions: the majority of consultants and senior registrars were wearing rose-tinted spectacles when they completed their ballot papers

W J HARRISON

North Middlesex Hospital,

North Middleser
London N18

** The virtues and shortcomings of the new contract were discussed at considerable length in our correspondence columns during the period leading up to the ballot.-ED, $B M \mathcal{F}$.

\section{Future of British anaesthetics}

SIR,-Dr Ian Hine (1 July, p 60) has been upset by my comments, but if he were to think deeply on the subject he might realise that I want to improve the status and job satisfaction of consultant anaesthetists in Britain by relieving them of the routine anaesthetic so that their very hard-learnt experience and training can be used (1) in those difficult cases where they are needed, (2) in the intensive care unit, and (3) in the accident department. That is, so that they become what in fact they are, consultants in emergency medicine.

If they relegate their more mundane work to people like me (who would enjoy it enormously), then they would truly become what they are capable of being: the most demanding and exciting specialty of all hospital medicine.

\section{C HogG}

Bristol only to fulfil teaching and research commitments but also to perform tasks which require medical registration and membership of a medical defence organisation.

\section{A solution for preclinical departments}

SIR,-A further way in which parity can be achieved between clinical and preclinical medical teachers (Dr B R MacKenna, 1 July, p 72) is to pay them for their involvement in clinical teaching. This participation could be increased with benefit to the patient, the student, and the clinician.

Eight years ago I had the task of reorganising the final-year clinical curriculum in the Liverpool Medical School. I sought the help of the preclinical teachers who attended regular weekly student seminars with the clinicians in the hospital. On one occasion a man of 32 with a lump in his neck and hypertrophied rugae who complained of passing bright red blood per rectum puzzled the assembled clinicians. Bronchoscopy and gastroscopy were not helpful. The physiologist present, Professor R A Gregory, thought he had a malignant gastrinoma attached to his transverse colon and hoped to confirm it by an estimation of his serum gastrin concentration, which he could get done in America. Of course it was confirmed and the patient's management greatly assisted. When the patient died about 18 months later at a weekend, Professor Gregory himself recovered the tumour. He and his preclinical colleagues received, and as far as I know still receive, no remuneration for these seminars extending into the early evening. He could not at that time get the necessary money to enable him to estimate the serum gastrin although he synthesised gastrin and could make a clinical diagnosis.

Surely the time has come to recognise the important contribution of medically qualified preclinical teachers to medical education and to broaden the conception of their role in patient care. A way must be found to reward their talents and recognise real distinction in so numerically small a number of our profession.

Baldrine, IOM

JAMES MORONEY

SIR,-I read with interest Dr B R McKenna's article (1 July, $p$ 72). The idea deserves careful consideration, but I feel that I must point out an inaccuracy. He writes, when considering non-medically qualified staff, "It would be iniquitous for two groups doing the same job in the same department to be placed on different salary scales."

Medically qualified staff are required in many preclinical departments to bear clinica responsibility in a number of ways: (a) for medical students in the performance upon each other of physiological procedures, which experiments form an essential part of the undergraduate curriculum; $(b)$ for patients sent from hospital, without hospital medica staff in attendance, for investigative physiological tests; (c) for human subjects in physiological research. ASTMS insists that medically qualified staff be to hand so that its member will never be called upon to take responsibility in an emergency.

Taking all this into consideration it is clea that for many departments Dr McKenna's assertion is false. Medically qualified staf
W S MONKHOUSE Nottingham Preclinical Representative to the Conference of Medica

Department of Human Morphology University Hospital and Medical School,

\section{Item-of-service payments to general} practitioners

SIR,-I wonder whether you can tell me whether the BMA has ever attempted to persuade the Department of Health and Social Security to pay general practitioners for two very important items of service-namely, electrocardiograms and pregnancy tests.

Over the years general practitioners must have saved the DHSS many thousands of pounds by doing ECGs for no direct reimbursement on machines owned by themselves and using paper paid for by themselves. The callous acceptance of this state of affairs by successive Ministers of Health seems to me to be typical of the cheap and shoddy way the NHS is run.

That it is also very inefficient is perhaps more important, because I am sure many more GPs would do ECGs on their own machines if a realistic charge could be made either to the patient or to the DHSS. Similarly I am sure many GPs would do pregnancy tests for their patients if they could be reimbursed their costs. It seems odd that pharmacists in a private capacity can charge patients for doing these tests whereas the patient's own doctor has to refuse to do the test. The latter could be done at the initial consultation, so saving the patient considerable trouble and possibly travelling expenses also in the case of rural patients.

Why is this ridiculous state of affairs allowed to continue?

Lakenheath, Suffolk

J P H ANDERSON

***The Secretary writes: "The extension of item-of-service payments to cover these and other services provided by general practitioners has been pursued with the Health Departments on a number of occasions in recent years. The Departments have been extremely reluctant to agree to any extension of the range of item-of-service payments in general practice, but this is a question which is currently being studied by the New Charter Working Group of the General Medical Services Committee."-ED, BMF.

\section{Unfinished business}

SIR,-Am I alone among the grass roots of the Association in finding, with occasional exceptions, the Annual Report of Council (22 April, p 1065) lacking in urgency and relevance? In the theatre of yesteryear we waited for Godot and I feel the Association is waiting for the 1979 Review Body and the Royal Commission.

Why can't the BMA start discussions on the abolition of multidistrict areas as agreed by the Representative Body in Motion 239 